\title{
Sustainable Health Development through Health Education: Universities' Role in Curriculum Development with Ecological Public Health Principles
}

Alice ML Li ${ }^{*}$

Technological and Higher Education Institute of Hong Kong, Hong Kong SAR, PR China

*Corresponding author: Alice ML Li, Technological and Higher Education Institute of Hong Kong, Hong Kong SAR, PR China, Tel: +85221761857; E-mail: lialice6@gmail.com

Received date: August 15, 2018; Accepted date: August 21, 2018; Published date: August 28, 2018

Copyright: (c) $2018 \mathrm{Li} \mathrm{AML}$. This is an open-access article distributed under the terms of the Creative Commons Attribution License, which permits unrestricted use, distribution, and reproduction in any medium, provided the original author and source are credited.

\begin{abstract}
As the traditional healthcare professionals' role in the functions of healthcare setting is being established intensely based on 'Bio-medical' Model of disease-oriented focuses from the past epidemiological transition in the epochs. The gradual shift in disease patterns characteristic of different stages of epidemiological transition are by no means simple, as projected from the Age of (i) Pestilence and famine, (ii) Preceding Pandemics, (iii) Degenerative and Man-Made Diseases, and (iv) Delayed Degenerative Diseases. However, the foresight of the latest transition in this 21st Century is now emerged, in which environmental and climate mediated health risks have increasingly become a priority for the health implications with actual and potential catastrophic and highly complex dynamics of direct and indirect effects on widely diverse health impacts. In this regards, the establishment of ecological public health is crucial to modern public health. This paper proposed a newly emerging role for healthcare professionals to integrate ecological public health education as holistic vision and action agenda towards sustainable ways of living for sustainable health development. The role of Universities in curriculum development by integrating and transforming these epistemology competencies through health education agenda, as capacity building in support of sustainable health development is entirely indispensable.
\end{abstract}

Keywords: Health education; Ecological public health; Curriculum development in universities

\section{Introduction}

The burden of current health care systems substantially struggle to keep up with the changing patterns of various diseases that result both from a rapidly changing and degraded Earth and from the way people live as well [1]. The growing burden of both communicable and noncommunicable diseases has become more evident, and the links between health and economic development have become increasingly recognized [2]. Environmental and climate mediated health risks have increasingly become a priority for our health implications. The impacts of global environmental changes have been identified as the rising health threats that are potentially catastrophic and highly complex with global drivers and different underlying ecological determinants in relation to social, economic, technological advancements and developments, in addition to more intensifying human-induced anthropogenic activities per se [3]. In fact, different stages of epidemiological and health transitions are the collective and collaborative efforts to reorient the picture of changes in morbidity and mortality, as well as the projected underlying health threats of the situation.

Since many of the key determinants of health and disease provide insights into the fundamental problems in health transition, whilst an epidemiological transition enhances our concepts of diseases that are continuously evolving in diverse ways with many scientific investigations and findings supported, refined and unfolded our progressive understandings in the influence of the eco-environments on human health [3]. Consequently, ecological reasoning as a developing theme in the sciences and arts, which must apply to epidemiology for an appreciation of complexity in the enhancement of public health thinking that human and ecosystems health is interdependent [4].

To build sustainable future is a central plank of public health in reconnecting the value of environment into public health for our longterm benefits, which are indeed flip sides of the same coin for the creation of supportive environments to ensure positive benefit to the health of the public [2]. As the WHO reinforced the Ottawa Charter, in which stated, "Our societies are complex and interrelated. Health cannot be separated from other goals; the inextricable links between people and their environment constitutes the basis for a socioecological approach to health" [5]. Therefore, the frame of reference for the value of the social-ecological model in guiding how best to align the components of an integrated health service should also be reflected in the health policies and professional education systems of all nations, as the cornerstones of sustainable health systems from a global perspective [6].

From this perspective, sustainable health development is the most critical issues facing global society and look set to increase in importance for this and future generations. As climate change, land, water, air, microbial activity, which cannot be disconnected from the health of everyone and everything else, as this ecological thinking helps public health by accepting the normality of complex interactions that must coexist [4].

This paper proposed a newly emerging role for healthcare professionals to integrate ecological public health education into sustainable health development as holistic vision and action agenda towards sustainable ways of living. It is also recommended Universities' pioneer role of curriculum development in integrating and transforming these epistemology competencies through health 
Page 2 of 7

education under this new stage of epidemiological and health transition. In fact, the emergent role of higher education as a key setting that represents one large-scale and hugely influential sector with enormous impact and potential to addressing their challenges in an integrated and coherent way for promoting health and sustainability positively [7].

\section{The Age of Environmental and Climate Mediated Health Risks}

The impacts of global environmental change on human health are widely understood and increasingly well documented, the world is facing the unprecedented challenges associated with environmental and climate mediated health risks, and therefore a new ecological sense of public health based on the recognition of the limits on nature is emerged [8]. This significant part of ecological factors certainly includes climate change, air, water and soil pollutions, stratospheric ozone depletion, and the loss of biodiversity, pollution and eco-toxicity. In fact, all of which alters the physical and eco-environments, in turn affects the vital parts of ecological processes and natural resources, as well as adequate amounts of their natural functions [2,8-10] which include:

- The most basic level of oxygen, water and food.

- The ozone layer that protects Earth's surface from high levels of UV radiation.

- Changes in hydrological systems and the supplies of freshwater.

- Land degradation and reduction of abundant fertile soil.

- Disturbance of marine aquatic systems with acid emissions affect ocean and freshwater acidification, and damages to coral reefs.

- Nitrogen and phosphorus cycles that circulate nutrients needed for plants and food.

- Systems to detoxify wastes through natural processes, e.g. many organic chemicals become the ecotoxic substances and environmental contaminants such as organic pollutants and some heavy metals, which can be bio-concentrated up the food chain.

- Reasonably stable global climate with temperature conducive to human and other life forms.

- Air pollution with source of precipitation.

- Water and food borne diseases.

- Vector borne diseases.

- Stresses on food-producing systems from other risks associated environmental contaminants such as misuses of antibiotics, pesticides, fertilizers.
Additionally, the global dietary trends are also a problem, as the consumption of animal-sourced food products by humans is one of the most powerful negative forces affecting the conservation of terrestrial ecosystems and biological diversity, which is one of the leading causes of Greenhouse gas emissions from livestock production [11]. All these global environmental changes include not only climate change but natural resources depletion, pollutions, eco-toxicity, and loss of species and biodiversity, which are caused by human-induced anthropogenic activities in the changes to ecosystem function that have also been called the Anthropocene [12].

As concepts of diseases are developed at different stages throughout the history of public health developments [8], and this new epoch under the Age of environmental and climate mediated risks imposed global burdens of direct and indirect profound effects on our health, as shown in Figure 1 [3].

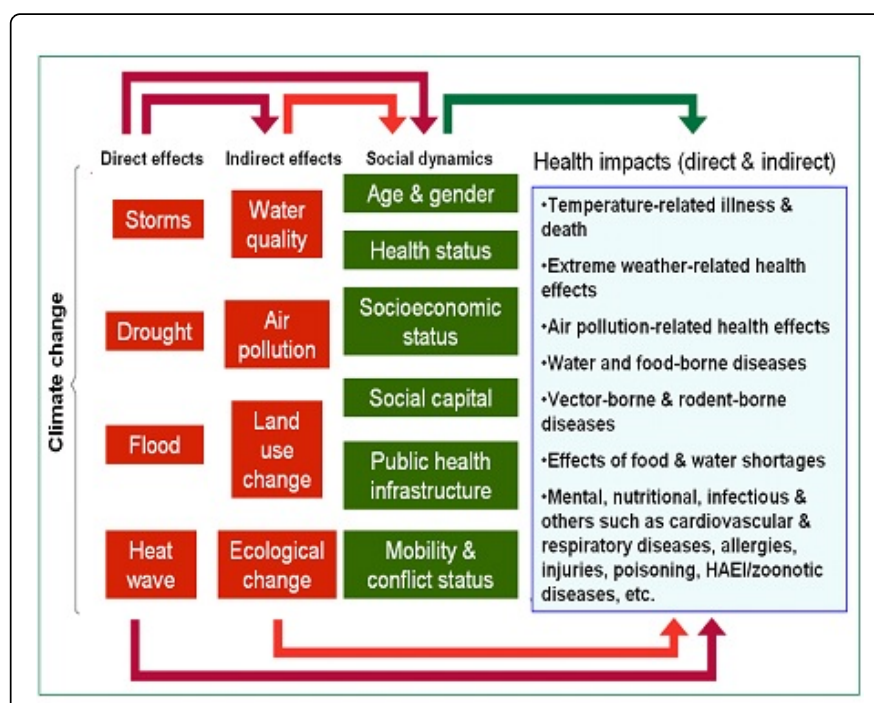

Figure 1: The direct and indirect effects of health impacts from climate change [3].

All these human-induced changes give to unprecedented threats to our health of the world's population in the $21^{\text {st }}$ century [12], as the Canadian Public Health Association estimated the populations at risk from the only selected major examples of the adverse health impacts of Global Environmental Changes (GECs) are enormous as shown in Table $1[10]$.

\begin{tabular}{|c|c|c|}
\hline Category of health risk & $\begin{array}{l}\text { Size/ proportion of population } \\
\text { at risk }\end{array}$ & Types of Global Environmental Changes (GECs) involved \\
\hline Malaria & $40 \%$ or world population & Climate change and land use change \\
\hline Dengue fever & 3 billion & Climate change, urbanization, world trade \\
\hline Diarrhoeal diseases (associated with water quality/quantity) & 1 billion people & $\begin{array}{l}\text { Climate change, land cover change, pollution, irrigation and } \\
\text { freshwater shortage, biodiversity change }\end{array}$ \\
\hline Malnutrition (especially food shortages) & 840 million & Climate change, land use, land cover change \\
\hline $\begin{array}{l}\text { Health consequences of desertification: malnutrition; respiratory } \\
\text { diseases; impacts of population displacement }\end{array}$ & 250 million people & Stratospheric ozone depletion \\
\hline
\end{tabular}


Table 1: The global estimated numbers of people at risk [10].

However, one important factor that complicates the picture, as given the current trends in ecosystem functioning, and the overall health impacts will grow with the real danger lies in sudden, rapid and largely unpredictable, non-linear changes that might also occur as we pass the tipping point of ecological boundaries [13]. As this sense of direction is in line with the ecological paradigm, with which supports the sustainability of eco-environments as well as climate-dependent ecosystems that connect and sustain all forms of life on our planet earth, and it will respond when pushed beyond critical limits, Figure 2 shows these limits of planetary boundaries [8].

\begin{tabular}{|c|c|c|c|c|}
\hline \multicolumn{5}{|c|}{ Planetary Boundaries } \\
\hline Earth system process & Parameters & $\begin{array}{l}\text { Proposed } \\
\text { boundary }\end{array}$ & $\begin{array}{l}\text { Current } \\
\text { value }\end{array}$ & $\begin{array}{l}\text { Pre-industrial } \\
\text { value }\end{array}$ \\
\hline Climate change & $\begin{array}{l}\text { Atmospheric } \mathrm{CO} 2 \text { concentration (parts per } \\
\text { million by volume) }\end{array}$ & 350 & 387 & 280 \\
\hline Rate of biodiversity loss & $\begin{array}{l}\text { Extinction rate (number of species per } \\
\text { million species a year) }\end{array}$ & 10 & $>100$ & $0.1-1$ \\
\hline Nitrogen cycle & $\begin{array}{l}\text { Amount of } \mathrm{N} 2 \text { removed from atmosphere } \\
\text { for human use (millions of tons per year) }\end{array}$ & 35 & 121 & 0 \\
\hline Phosphorus cycle & $\begin{array}{l}\text { Quantity of P flowing into oceans (millions } \\
\text { of tons per year) }\end{array}$ & 11 & $8.5-9.5$ & .1 \\
\hline $\begin{array}{l}\text { Stratospheric ozone } \\
\text { depletion }\end{array}$ & Concentration of ozone (Dobson unit) & 276 & 283 & 290 \\
\hline Ocean acidification & $\begin{array}{l}\text { Global mean saturation of aragonite in } \\
\text { surface sea water }\end{array}$ & 2.75 & 2.90 & 3.44 \\
\hline Global freshwater use & $\begin{array}{l}\text { Consumption of freshwater by humans } \\
\text { (km3 per year) }\end{array}$ & 4000 & 2600 & 415 \\
\hline Change in land use & $\begin{array}{l}\text { Percentage of global land cover converted } \\
\text { into eropland }\end{array}$ & 15 & 11.7 & Low \\
\hline
\end{tabular}

Figure 2: Indications on Limits of Planetary Boundaries [14] as quoted [8].

The impacts of public health arising from this environmental crisis of global climate change, together with the complexity of epidemiological transition to the significance of the environmental conceptualization of health that leads to immense challenges forced on the ecological dimensions for healthful practices [8]. For instance, numerous scientific studies have increasingly recognized that many childhood diseases are, in fact, caused by environmental hazards, and therefore healthcare professionals need to be aware of environmental causes of childhood morbidity and mortality and to equip themselves for these new challenges in child health [15].

Perhaps, the time between conception and birth is one of the most vulnerable life stages, during which the environment may have tremendous immediate and lasting effects on health [16]. The following Figure 3 summarized the timing of air pollution risks in relation to different trimester gestational stages of the fetal growth in association with morphological abnormalities and functional defects in their later developmental stages.

Therefore, it is the recommended fact that ecological health should be integrated into already existing biopsychosocial medicine, as the fundamental importance of ecology to medicine as the evidence shows that a tremendous increase in the kinds and numbers of diseases which are brought about directly by pollution and poisoning of mankind's environment [1].

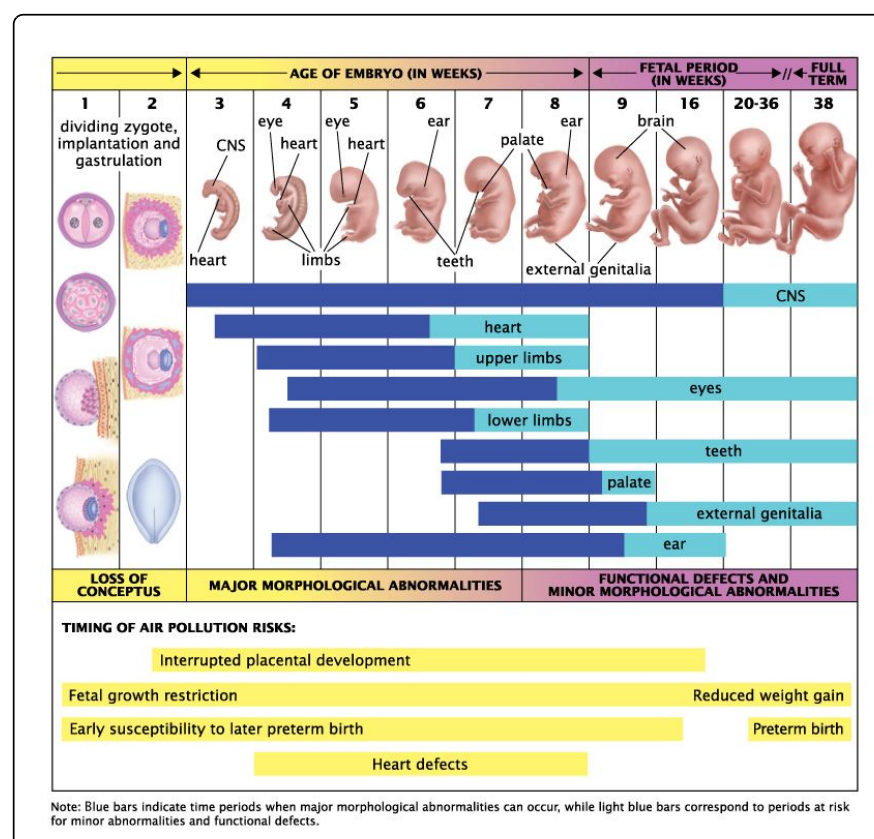

Figure 3: Fetal development and timing of air pollution risks [16].

\section{Health Education Agenda towards Sustainable Health Development for a Changing Society}

Health is crucial for sustainable human development both as an inalienable human right and as essential contributor to the economic growth of society through productive employment, reduced expenditure on illness care and greater social cohesion by promoting good health at all ages and the benefits of development extend across generations [17]. As the Public health's role is to protect and promote health, prevent disease and injury and reduce inequalities in health by encouraging and supporting the transition to a sustainable, just and healthy future [13]. The new epoch of epidemiological transition in this 21 st Century is now emerged, in which environmental and climate mediated health risks have increasingly become a priority for the health implications with actual and potential catastrophic and highly complex dynamics of direct and indirect effects on widely diverse health impacts under this transition [3]. The establishment of ecological public health is crucial to modern public health and is already overdue [18].

Health education research and development should be able to accommodate towards the changing patterns of health needs and its application in public health means in practice for population health. 'Health for all by the year 2000' was clearly not achieved, and henceforth $\mathrm{WHO}$ has reforecast its endeavors with targeted date further to 2020, and "the emphasis in public health in this revised focus includes sustainable development, collaboration, protection, 
prevention, resilience, adaptation, the emergence of chronic diseases and the re-emergence of infectious diseases" [19].

Over the past decades, there has been a growing understanding and recognition of the importance of disease prevention and health promotion internationally. it is the relevant time frames of education for improving knowledge in public health and ecological health, as this gaze further into the future and the past, ultimately already reaching evolutionary time scales, as life depends substantially on ecological systems [1].

According to the declaration of Alma-Ata, the distinctive features of primary care is responding to the challenges of a changing world with four sets of Primary Health Care (PHC) reforms as driven by demand [20]. A renewal of PHC is the palpable demand, as globalization is putting the social cohesion of many countries under stress, and "health systems as key constituents of the architecture of contemporary societies" [20]. After years of relative neglect for the significance of the expected on-going PHC reforms, a new start with essential features of a strong health system based on the perspective of sustainable in health development led by primary health care should now be revitalized to serving the relevant and changing needs of our global community. In fact, that was creating supportive environments that we live our lives and it is these contexts or settings, which need to be made more conducive to health as also being illustrated in the 1986 Ottawa Charter for Health Promotion [21].

Primary healthcare as the key to addressing these challenges and ensuring sustainability to be achieved in the healthcare system is recognized, as the Royal Australian College of General Practitioners believed that well-supported primary healthcare, with the patient at the center, is the key to an efficient and effective healthcare system in improving the health outcomes [22]. As primary health care reflects and evolves from the sociocultural, economic and political characteristics of the country and its communities, which is essential as part of development in the spirit of health sustainability in respond to the expressed health needs of the community. As echoed to the aforementioned content in a "spirit of partnership and service to ensure primary health care for all people since the attainment of health by people in any one country directly concerns and benefits every other country", as in the declaration of Alma-Ata [23].

Henceforth, the process of community empowerment should be promoted with the principles of PHC approach, as a 'parallel track' alongside with the capacity building for enhancing and fostering the desirable health seeking behavior by promoting a greater sense of health awareness and joint responsibility from the 'People-centered' standpoint, as part of the role of ecological Public Health. The focused concerns of sustainable health development indeed will have broad spectrum with diverse focal point on healthy needs for the interest and synergistic health benefits to improve service delivery in achieving better health and wellness with emphasis on promotion, prevention and joint responsibility for furtherance in promoting system sustainability towards this transition.

Health education is any combination of learning experiences designed to help individuals and communities improve their health, by increasing their knowledge or influencing their attitudes for the health needs of a changing society. For this reason, the aims of education are purposeful for outcomes as inspirational vision or intent to educational actions that designed to achieve future 'product', 'behavior' and/or 'moral integrity' in order to foster love of humanity by providing knowledge and develop skills, attitudes, values essential to personal development and necessary for living in and contributing to a changing society.

\section{Role of Universities in Curriculum Development for Health Education Agenda}

"The success of public health work depends largely upon the character of the educational program executed" [24], while questioned for whether the principles underlying the educational program are effective in the cooperation of organized medicine is secured through education of the physician precedes public education with respect to new public health activities [25].

University should take this pioneer role in the evolving trends of innovative-driven curriculum development as a platform of a change process and drivers to nurture, cultivate and transform the necessary mentalities of perceptions and understandings towards this global direction of ecological sustainability in relation to sustainable public health development for a changing globalized society under this epidemiological and health transition. The significant questions of "What does the curriculum do to individuals and human society? has been put forward under this agenda [26]. In fact, curriculum is the center of reasoning that represents the cultural and authorized artifact with symbolized and corresponding value, significance and meaning, and therefore curriculum development acted as the educational practice blocks and model through the parameters of the University.

The term curriculum is from a Latin word for 'race-course' that refers to the course of deeds and experiences through which children grow to become mature; and in this sense, curriculum is all the selected activities done in the society which are used in the learning process [27]. Ecological public health approach for global climate change is the ways of learning towards sustainable living for global interdependence, which views as a new kind of humanism and that is utterly essential under the existing environmental crises [8].

Curriculum development is used as the defined basis for the connectivity of this new kind of humanism through health education agenda with focus on ecological public health principles as the directional indicator for this purposeful learning process. Trends of curriculum development should be served as this directional indicator through the educational practice blocks for the desirable change proactively, constructively, professionally and effectively to accommodate health education agenda under the global crisis of this new epoch. Therefore, health education reform is the key for the process of making this change through curriculum development to infuse the concepts of this paradigmatic shift as the holistic mapping of ecological public health principles for sustainable health development in our changing globalized society.

The valuable tool for enhancing such responsiveness to global environmental changes is meant to be in parallel with the integration of ecological public health principles and approaches through health education and its agenda incorporates into curriculum development to improve the limits on nature. In this sense, curriculum has become a dynamic process because of: (i) the changes that occur in our society, (ii) its potential impacts on students' Knowledge, Attitudes and Skills (KAS) that contribute towards their personal, academic and professional learning and competencies, (iii) important role in forging life-long learning competencies, health literacy as well as social attitudes. 
Universities can also embed health and sustainable development into their core business through means of curriculum development linked to research and knowledge exchange, which allows for transformative learning to take place [7]. As universities is regarded as the most legitimized social agent that creating, discovering, conveying, disputing, accepting and disseminating epistemology, especially through the innovative platform of curriculum development. Universities have the potential to play a leading role may either lead such approaches, or be key partners in an endeavors to empower and enable communities to develop more sustainable ways of living and working [28].

An empirical study based on a sample of universities in the United Kingdom, Germany, Portugal and Brazil examined the extent to which capacity building for sustainable development is being undertaken with conclusion that universities have a critical role to play in prioritize the sustainability agenda in community development [28]. As universities are regarded as integral part of the global economy, as they prepare most of the professionals who develop, manage and teach in society's public, private and non-government institutions, thus they are in an unique positions to influence the direction we choose to take as a society; in fact, the university campuses are just like small cities, their impacts can be substantial [2].

In view of this influential fact and responsibility, these processes of 'input-throughput-output' for health education with ecological public health principles and approaches support the new understanding of widened knowledge and concepts of sustainable health development in response to the focused needs to prioritize the sustainability agenda. As Fleming et al. [2] mentioned that "there are two ways in which sustainability can be incorporated into university teaching: one is to ensure that all degree programs produce sustainability-literate graduates, and the other is to produce some sustainability specialists."

Education means the formation of understanding as a response to the calling of being which is the end of our knowing, and as the continuous revitalization of learning about life, and to know is to comprehend being in its totality [27]. Curriculum development as changing agents, with continuation of the existence of individual growth, development, and learning for 'Learning to know', 'Learning to do', 'Learning to live together' and 'Learning to be', as using the format of "Four pillars of a new kind of education" in support of the global agenda on 'Education for Sustainable Development' as in the Delors Report [8].

In fact, a viable education can only be an integral education of the human being, is therefore recommended transdisciplinarity in education and the concept of 'A Culture for Health' for enhancement and empowerment in the cultivation of the intended accountable behaviors as part of sustainable ways of living for global interdependency [3]. By "instilling complex and transdisciplinary thought into the structures and programs of the university will permit its evolution toward its somewhat forgotten mission today - the study of the universal," which is a new kind of humanism [29]. In this connection, the agenda of health education towards sustainable living for global interdependence are also viewed as 'a new kind of humanism' that is utterly essential under the existing environmental crises of climate change in this latest stage of epidemiological and health transition.

Environmental and health education share many educational means and ends with common goals, common responsibility and challenges on the level of curriculum development in theorizing with different level of pedagogical practice from perspectives of the epistemological, the transformative, the dialectical and the holistic [30]. Therefore, public health, sustainability and climate change agendas are inextricably linked that they need to be considered as one broad overarching system, which adopts an ecological model of health as the synergistic solutions, and as a means of furthering and facilitating this synergy, which will increasingly become the emerging role of higher education [7].

\section{Perspectives from Hong Kong: A Need for Ecological Public Health Education}

In Hong Kong, the Government believed that the community to work hand in hand to build up an environment that makes healthier choices easier with the guiding public health concepts in linking health promotion and disease prevention with the total environment, as for an important determinant of people's health is the environment in which people live, learn and work [31]. The WHO regards the growth of metropolitan areas as a major determinant of population health, as many issues arising from infrastructure, land use, building regulations, transportation systems, fuels and energy consumption, mixed residential and industrial areas, of which the management of urban environments to underpin health protection [32].

Hong Kong is one of the affluent international cities, the second largest ecological footprint in Asia, with about 3.9 earths would be needed to sustain humanity's lifestyle if everyone consumed at the same rate as Hong kongers [33]. There are very large health costs to our current way of life, for instance, whatever we generate as waste is re-incorporated within the natural systems of which we are a part [13]. All these environmental hazards are the obstacles for our hopes for sustainable health protection [32].

In addition, medical technologies and medical care also consume large amounts of natural resources, electricity, produce a large and toxic waste stream, and pollute the air, water, sediments, soils with mercury, dioxin, toxic flame retardants as well as a variety of pharmaceuticals [1]. Those waste's detoxification or degradation may require decades to millennia and during which the waste can cause great harm to the environment, hence the health co-benefits of a more sustainable society is utterly desirable [13]. The shift to a more ecologically sustainable society results in health gains from a healthier way of living is the message of hope [12].

In light of this view, a need for ecological public health education reform in Hong Kong will be a challenge for achieving the synergistic health benefits that imperative towards the international trends of sustainable health development. For instance, Hong Kong's Climate Action Plan 2030+ has been setting a target to reduce our carbon intensity by between $65 \%$ and $70 \%$ by 2030 , as HK wants to moving along the "low carbon" pathway to become an economy based on low energy consumption and low pollution [34].

In this regard, professional development should incorporate with the changing healthcare demands and needs that correspond to the values pursue that required fundamental changes in the way healthcare systems operated and harnessed the potential of other sectors [20], and contribute to advancing health and wellness in line with the values and vision of ecological public health education. As it is equally important for health education sectors, especially the University to have a view of needs and to take the lead as the pioneer to anticipate into this evolution in order to enable and ensure that integrations are in place to 
support the direction towards this epidemiological and health transition.

\section{Conclusion}

Public health focuses on communities, and ecological health is a new basis for education and prevention, medicine indeed has considered the natural environment per se as important only when it became obvious that it was directly affecting the health of humankind [1]. A better understanding of the potential health effects of global environmental change is only just emerging, and a number of causal pathways mediates these health effects [35], we need to act with the knowledge and understanding that the health impacts under this new epoch of environmental and climate mediated health risks.

There are range of ways in which public health can contribute to sustainability of the environment and address the impacts of significant social and environmental change on the public's health in this educational agenda, such as the role for universities through undergraduate and postgraduate education, and continuing professional practice education, particularly in public health arena [2].

Historically, health education and promotion carried out with established channels to reach defined populations in some particular settings such as at workplaces, schools, community health centers, hospitals and even in prisons as well for many years. The concept of using different settings approach meant to seek systemic changes to the whole environment for the sake of facilitating the ultimate goal of health promotion through education. This paper proposed the synergistic health benefits for integrating ecological public health principles as the vision and action agenda for health education.

University should recognize the importance of its role, function under the domain of health education, research and development to these emerging health concerns globally, and take the lead and responsibilities to adopt the diverse health knowledge orientations, values and attitudes as a way forward for sustainable health development. Health education agendas and initiatives, in fact, are the preponderance of this ultimate goal of this paper, with directions to support a newly emerging role for healthcare professionals to integrate ecological public health education into sustainable health development as holistic vision and action agenda towards sustainable ways of living through the curriculum development under the parameters of universities.

\section{Conflict of Interest}

The author declares no any actual or potential conflict of interest in this paper.

\section{References}

1. Schaller B, Sandu N (2011) Clinical medicine, public health and ecological health: a new basis for education and prevention?. Archives of Medical Science: AMS 7: 541-545.

2. Fleming ML, Tenkate T, Gould T (2009) Ecological Sustainability: What Role for Public Health Education?. Int J Environ Res Public Health 6: 2028-2040.

3. Li AML (2018) Public Health and Epidemiological Transition: Environmental and Climate Mediated Risks. International Journal of Advances in Science Engineering and Technology 6: 45-50.

4. Rayner G, Lang T (2015) Ecological public health: leaders, movements and ideas to shift the boundaries between the normal and the desirable.
In Healthy people, places and planet: reflections based on Tony McMichael's four decades of contribution to epidemiological understanding 2015. ANU Press, Canberra, pp: 617-642.

5. WHO (1986) Ottawa Charter for Health Promotion. Copenhagen: WHO Europe.

6. White F (2015) Primary Health Care and Public Health: Foundations of Universal Health Systems. Medical Principles and Practice 24: 103-116.

7. Orme J, Dooris M (2010) Integrating health and sustainability: the higher education sector as a timely catalyst. Health Education Research 25: 425-437.

8. Li AML (2017) Ecological Public Health Approach for Global Climate Change: A New Perspective of Transdisciplinarity. Glob Environ Health Saf 1: 1-11.

9. Li AML (2017) Ecological Determinants of Health: Food and Environment on Human Health. Environ Sci Pollut Res 24: 9002-9015.

10. Canadian Public Health Association (2015) Global Change and Public Health: Addressing the Ecological Determinants of Health. Canada: CPHA.

11. Li AML (2016) Health Promotion of Sustainable Diets: Key for Obesity Epidemic and Environmental Sustainability. J Nutr Health Food Eng 4: 00126.

12. Hancock T (2016) Public health in the Anthropocene: An eco-social approach to population health promotion in the 21 st century. presented at JASP, Montreal 22 November 2016.

13. Hancock T, Spady DW, Soskolne CL (2015) Global Change and Public Health: Addressing the Ecological Determinants of Health: The Report in Brief.

14. Schroeder K, Thompson T, Frith K, Pencheon D (2013) Chapter 1: Greening the gaze. In: Schroeder K, Thompson T, Frith K, Pencheon D (eds.) Sustainable Healthcare. UK \& USA: John Wiley and Sons Ltd.

15. Chan CW, Wong LHL (2015) Overview of Summit on Child Health and the Environment 2014. HK J Padiatr 20: 95-104.

16. Ritz B, Wilhelm M (2008) Air Pollution Impacts on Infants and Children. UCLA Institute of the Environment.

17. The Health for All Thematic Group of the Sustainable Development Solutions Network (SDSN) (2014) Health in the framework of sustainable development. February 2014

18. McMichael AJ, Butler CD, Dixon J (2015) Climate change, food systems and population health risks in their eco-social context. Public Health 129: 1361-1368.

19. Fleming ML, Parker E (2009) Introduction to Public Health E-Book. Elsevier Australia.

20. WHO (2008) Primary Health Care: Now More than Ever.

21. Naidoo J, Wills J (2009) Foundations for Health Promotion. China: Elsevier Limited.

22. The Royal Australian College of General Practitioners (2015) Vision for general practice and a sustainable healthcare system. Australia: The Royal Australian College of General Practitioners.

23. WHO (1978) Report of the International Conference on Primary Health Care, Alma-Ata, USSR.

24. Applewhite CC (1937) Replace Misinformation and Superstition-Under "Cooperative Health Work". American Journal of Public Health 27: 525.

25. Turner CE, Stimpson MR (1940) Evaluating the Health Education Program of a Health Department. American Journal of Public Health 30: 771-774.

26. Hyun E (2011) Transdisciplinary higher education curriculum: a complicated cultural artifact. Research in Higher Education Journal 11: 1-19.

27. Ogwora ET, Kuria G, Nyamwaka E, Nyakan B (2013) Philosophy as a key instrument in establishing curriculum, Educational policy, objectives, goals of education, vision and mission of education. Journal of Education and Practice 4: 95-102.

28. Shiel C, Leal Filho W, Do Paco A, Brandli L (2016) Evaluating the engagement of universities in capacity building for sustainable development in local communities. Eval Program Plann 54: 123-34. 
Citation: Li AML (2018) Sustainable Health Development through Health Education: Universities' Role in Curriculum Development with Ecological Public Health Principles. J Health Educ Res Dev 6: 270. doi:10.4172/2380-5439.1000270

Page 7 of 7

29. Nicolescu B, Ertas A (2013) Transdisciplinary Theory and Practice. USA The Academy of Transdisciplinary Learning \& Advanced Studies Publishing.

30. Mogensen F (1997) Critical thinking: a central element in developing action competence in health and environmental education. Health Education Research 12: 429-436.

31. Department of Health (2016) Promoting Health in Hong Kong: A strategic Framework for Prevention and Control of Non-communicable Diseases. HK: Department of Health.
32. Hedley AJ, Lai HK, Thach TQ, McGhee S, Wong CM (2013) Adverse health effects of the urban Hong Kong environment, HK: School of Public Health, The University of Hong Kong.

33. South China Morning Post (2016) How many earths do we need if the rest of the world consumed as much as Hong Kong?.

34. Environmental Protection Department (2018) Hong Kong: The FactsEnvironmental Protection. HK: Environmental Protection Department.

35. Mackenbach JP (2007) Global environmental change and human health: a public health research agenda. J Epidemiol Community Health 61: 92-94. 